IOANNIS K. Argyros (Lawton, OK)

\title{
ON THE CONVERGENCE AND APPLICATION OF STIRLING'S METHOD
}

Abstract. We provide new sufficient convergence conditions for the local and semilocal convergence of Stirling's method to a locally unique solution of a nonlinear operator equation in a Banach space setting. In contrast to earlier results we do not make use of the basic restrictive assumption in [8] that the norm of the Fréchet derivative of the operator involved is strictly bounded above by 1 . The study concludes with a numerical example where our results compare favorably with earlier ones.

1. Introduction. In this study, we are concerned with the problem of approximating a locally unique fixed point $x^{*}$ of the equation

$$
F(x)=x,
$$

where $F$ is a Fréchet differentiable operator defined on an open convex subset of a Banach space $X$ with values in $X$.

Stirling's method [10]

$$
x_{n+1}=x_{n}-A_{n}^{-1}\left(x_{n}-F\left(x_{n}\right)\right), \quad A_{n}=I-F^{\prime}\left(F\left(x_{n}\right)\right) \quad(n \geq 0)
$$

has been used to generate a sequence converging to $x^{*}[1]-[4]$, [8]. In particular elegant local and semilocal convergence results have been given in [8] under the restrictive assumption that $\left\|F^{\prime}(x)\right\|$ is strictly bounded above by 1 . Moreover in the same study a favorable comparison between Stirling's and Newton's methods was given including examples where Stirling's method converges but Newton's fails to do so. Note that both methods require almost the same computational cost: the evaluation of $F, F^{\prime}$ and the solution

2000 Mathematics Subject Classification: 65B05, 65G99, 65J15, 65N30, 65N35, 47H17, $49 \mathrm{M} 15$.

Key words and phrases: Stirling's method, Banach space, Fréchet derivative, majorizing sequence, Newton's method, convergence radius. 
of a linear equation at each step. Here we provide a new local and semilocal convergence analysis for method (2) without making use of $\left\|F^{\prime}(x)\right\|<1$.

Finally we provide a numerical example where our results compare favorably with earlier ones [7], [8], [10].

2. Semilocal analysis of Stirling's method. We provide the following result on majorizing sequences for Stirling's method (2).

Theorem 1. Assume that there exist parameters $L_{0} \geq 0, L \geq 0$ with $L_{0} \leq L, \eta \geq 0$, and $\delta \in[0,1]$ such that

$$
\left(\delta L_{0}+L\right) \eta \leq \delta .
$$

Then the iteration $\left\{t_{n}\right\}(n \geq 0)$ given by

$$
\begin{aligned}
& t_{0}=0, \quad t_{1}=\eta, \\
& t_{n+2}=t_{n+1}+\frac{L\left(t_{n+1}-t_{n}\right)^{2}}{2\left(1-L_{0} t_{n+1}\right)} \quad(n \geq 0)
\end{aligned}
$$

is non-decreasing, bounded above by $t^{* *}=2 \eta /(2-\delta)$, and converges to some $t^{*}$ such that

$$
0 \leq t^{*} \leq t^{* *} .
$$

Moreover, the following error bounds hold for all $n \geq 0$ :

$$
0 \leq t_{n+2}-t_{n+1} \leq \frac{\delta}{2}\left(t_{n+1}-t_{n}\right) \leq\left(\frac{\delta}{2}\right)^{n+1} \eta .
$$

Proof. The result clearly holds if $\delta=0$ or $L=0$ or $\eta=0$. Assume $\delta \neq 0$, $L \neq 0$ and $\eta \neq 0$. We must show that for all $k \geq 0$,

$$
\begin{aligned}
& L\left(t_{k+1}-t_{k}\right)+\delta L_{0} t_{k+1} \leq \delta, \\
& t_{k+1}-t_{k} \geq 0, \quad-L_{0} t_{k+1}>0 .
\end{aligned}
$$

Estimate (6) then follows immediately from (4) and (7). We use induction on $k$. For $k=0$ we have

$$
\begin{aligned}
& L\left(t_{1}-t_{0}\right)+\delta L_{0} t_{1}=L \eta+\delta L_{0} \eta \leq \delta, \\
& t_{1} \geq t_{0}, \quad 1-L_{0} \eta>0 \quad(\text { by }(3)) .
\end{aligned}
$$

But then (4) gives

$$
0 \leq t_{2}-t_{1} \leq \frac{\delta}{2}\left(t_{1}-t_{0}\right)
$$


Assume (6) and (7) holds for all $k \leq n+1$. Then

(8)

$$
\begin{aligned}
L\left(t_{k+2}-t_{k+1}\right)+ & \delta L_{0} t_{k+2} \\
\leq & L \eta\left(\frac{\delta}{2}\right)^{k+1}+\delta L_{0}\left[t_{1}+\frac{\delta}{2}\left(t_{1}-t_{0}\right)+\left(\frac{\delta}{2}\right)^{2}\left(t_{1}-t_{0}\right)\right. \\
& \left.+\ldots+\left(\frac{\delta}{2}\right)^{k+1}\left(t_{1}-t_{0}\right)\right] \\
\leq & L \eta\left(\frac{\delta}{2}\right)^{k+1}+\delta L_{0} \eta \frac{1-(\delta / 2)^{k+2}}{1-\delta / 2} \\
\leq & L \eta\left(\frac{\delta}{2}\right)^{k+1}+\frac{2 \delta L_{0} \eta}{2-\delta}\left[1-\left(\frac{\delta}{2}\right)^{k+2}\right] \\
= & \left\{L\left(\frac{\delta}{2}\right)^{k+1}+\frac{2 L_{0} \delta}{2-\delta}\left[1-\left(\frac{\delta}{2}\right)^{k+2}\right]\right\} \eta
\end{aligned}
$$

By (3) and (8) it suffices to show

$$
L\left(\frac{\delta}{2}\right)^{k+1}+\frac{2 L_{0} \delta}{2-\delta}\left[1-\left(\frac{\delta}{2}\right)^{k+2}\right] \leq L+\delta L_{0}
$$

or

$$
\delta L_{0}\left\{\frac{2}{2-\delta}\left(1-\left(\frac{\delta}{2}\right)^{k+2}\right)-1\right\} \leq L\left[1-\left(\frac{\delta}{2}\right)^{k+1}\right]
$$

or

$$
\frac{2 \delta}{2-\delta}\left[1-\left(\frac{\delta}{2}\right)^{k+2}\right]-\delta \leq 1-\left(\frac{\delta}{2}\right)^{k+1}
$$

or

$$
\frac{(\delta-1)(\delta+2)}{2-\delta} \leq \frac{(\delta-1)(\delta+2)}{2-\delta}\left(\frac{\delta}{2}\right)^{k+1},
$$

which is true by the choice of $\delta$. Hence, the first estimate in (7) holds for all $n \geq 0$. We must also show that

$$
t_{k} \leq t^{* *}
$$

For $k=0,1,2$ we have

$$
t_{0}=0 \leq t^{* *}, \quad t_{1}=\eta \leq t^{* *}, \quad t_{2} \leq \eta+\frac{\delta}{2} \eta=\frac{2+\delta}{2} \eta \leq t^{* *} .
$$


Assume (9) holds for all $k \leq n+1$. It follows from (6) that

$$
\begin{aligned}
t_{k+2} & \leq t_{k+1}+\frac{\delta}{2}\left(t_{k+1}-t_{k}\right) \leq t_{k}+\frac{\delta}{2}\left(t_{k}-t_{k-1}\right)+\frac{\delta}{2}\left(t_{k+1}-t_{k}\right) \\
& \leq \ldots \leq t_{1}+\frac{\delta}{2}\left(t_{1}-t_{0}\right)+\ldots+\frac{\delta}{2}\left(t_{k}-t_{k-1}\right)+\frac{\delta}{2}\left(t_{k+1}-t_{k}\right) \\
& \leq \eta+\frac{\delta}{2} \eta+\left(\frac{\delta}{2}\right)^{2} \eta+\ldots+\left(\frac{\delta}{2}\right)^{k+1} \eta \\
& =\left[1+\frac{\delta}{2}+\left(\frac{\delta}{2}\right)^{2}+\ldots+\left(\frac{\delta}{2}\right)^{k+1}\right] \eta \\
& =\frac{1-(\delta / 2)^{k+2}}{1-\delta / 2} \eta<\frac{2}{2-\delta} \eta=t^{* *} .
\end{aligned}
$$

Moreover, we have

$$
L_{0} t_{k+2}<\frac{2 L_{0} \eta}{2-\delta}<1 \quad(\text { by }(3)) .
$$

Hence, the sequence $\left\{t_{n}\right\}(n \geq 0)$ is bounded above by $t^{* *}$. It also follows from (4) that $\left\{t_{n}\right\}(n \geq 0)$ is non-decreasing, and hence it converges to some $t^{*}$ satisfying (5).

That completes the proof of Theorem 1.

Below we show the main semilocal convergence theorem for Stirling's method (2).

Theorem 2. Let $F: D \subseteq X \rightarrow X$ be a Fréchet differentiable operator. Assume there exist a point $x_{0} \in D$ and parameters $\eta \geq 0, \ell \geq 0, \ell_{0} \geq 0$, $b \geq 0, a_{0} \in[0,1), \delta \in[0,1]$ such that:

(11) $A_{0}^{-1} \in L(X, X)$,

(12) $\left\|A_{0}^{-1}\left(x_{0}-F\left(x_{0}\right)\right)\right\| \leq \eta$,

(13) $\left\|F(x)-F\left(x_{0}\right)\right\| \leq a_{0}\left\|x-x_{0}\right\| \quad\left(a_{0}<1\right)$,

(14) $\left\|F^{\prime}(F(x))\right\| \leq b$,

(15) $\left\|A_{0}^{-1}\left[F^{\prime}\left(F\left(x_{0}\right)\right)-F^{\prime}(F(x))\right]\right\| \leq \ell_{0}\left\|F\left(x_{0}\right)-F(x)\right\|$,

(16) $\left\|A_{0}^{-1}\left(F^{\prime}(x)-F^{\prime}(y)\right)\right\| \leq \ell\|x-y\| \quad$ for all $x, y, F\left(x_{0}\right), F(x) \in D$,

(17) $\left(L+\delta L_{0}\right) \eta \leq \delta \quad$ for $L=(3+2 b) \ell, L_{0}=a_{0} \ell_{0}$,

(18) $\bar{U}\left(x_{0}, t^{*}\right)=\left\{x \in X \mid\left\|x-x_{0}\right\| \leq t^{*}\right\} \subseteq D$,

$$
t^{*} \geq \frac{\left\|x_{0}-F\left(x_{0}\right)\right\|}{1-a_{0}}
$$

where $t^{*}$ is given in Theorem 1 . Then $\left\{x_{n}\right\}(n \geq 0)$ generated by Stirling's method (2) is well defined, remains in $\bar{U}\left(x_{0}, t^{*}\right)$ for all $n \geq 0$, and converges 
to a fixed point $x^{*} \in \bar{U}\left(x_{0}, t^{*}\right)$ of the operator $F$. Moreover, the following error bounds hold for all $n \geq 0$ :

(20) $\left\|x_{n+2}-x_{n+1}\right\| \leq \frac{L}{2\left(1-L_{0}\left\|x_{n+1}-x_{0}\right\|\right)}\left\|x_{n+1}-x_{n}\right\|^{2} \leq t_{n+2}-t_{n+1}$,

$$
\left\|x_{n}-x^{*}\right\| \leq t^{*}-t_{n}
$$

where the sequence $\left\{t_{n}\right\}(n \geq 0)$ is generated by (4). If there exists $R>t^{*}$ such that

$$
\begin{gathered}
\bar{U}\left(x_{0}, R\right) \subseteq D, \\
\ell(1+b) \eta+a R+2 \ell_{0} a_{0} t^{*} \leq 2,
\end{gathered}
$$

$$
\|F(x)-F(y)\| \leq a\|x-y\| \quad \text { for all } x, y \in D \text { and some } a \geq 0,
$$

then the fixed point $x^{*}$ of the operator $F$ is unique in $U\left(x_{0}, R\right)$. Furthermore if $R=t^{*}$ and strict inequality holds in (23), then $x^{*}$ is unique in $\bar{U}\left(x_{0}, t^{*}\right)$.

Proof. Let us prove that

$$
\begin{gathered}
\left\|x_{k+1}-x_{k}\right\| \leq t_{k+1}-t_{k}, \\
\bar{U}\left(x_{k+1}, t^{*}-t_{k+1}\right) \subseteq \bar{U}\left(x_{k}, t^{*}-t_{k}\right),
\end{gathered}
$$

for all $k \geq 0$. For every $z \in \bar{U}\left(x_{1}, t^{*}-t_{1}\right)$,

$$
\left\|z-x_{0}\right\| \leq\left\|z-x_{1}\right\|+\left\|x_{1}-x_{0}\right\| \leq t^{*}-t_{1}+t_{1}=t^{*}-t_{0}
$$

implies $z \in \bar{U}\left(x_{0}, t^{*}-t_{0}\right)$. Since also

$$
\left\|x_{1}-x_{0}\right\|=\left\|A_{0}^{-1}\left(x_{0}-F\left(x_{0}\right)\right)\right\| \leq \eta=t_{1}-t_{0},
$$

(25) and (26) hold for $k=0$. Suppose they hold for $n=0,1, \ldots, k$. Then

$$
\left\|x_{k+1}-x_{0}\right\| \leq \sum_{i=1}^{k+1}\left\|x_{i}-x_{i-1}\right\| \leq \sum_{i=1}^{k+1}\left(t_{i}-t_{i-1}\right)=t_{k+1}-t_{0}=t_{k+1}
$$

and

$$
\left\|x_{k}+\theta\left(x_{k+1}-x_{k}\right)-x_{0}\right\| \leq t_{k}+\theta\left(t_{k+1}-t_{k}\right)<t^{*}, \quad \theta \in[0,1] .
$$

Note also that for $x \in \bar{U}\left(x_{0}, t^{*}\right)$,

$$
\begin{aligned}
\left\|x_{0}-F(x)\right\| & \leq\left\|x_{0}-F\left(x_{0}\right)\right\|+\left\|F\left(x_{0}\right)-F(x)\right\| \\
& \leq\left\|x_{0}-F\left(x_{0}\right)\right\|+a_{0}\left\|x_{0}-x\right\| \\
& \leq\left\|x_{0}-F\left(x_{0}\right)\right\|+a_{0} t^{*} \leq t^{*} \quad \text { (by (19)). }
\end{aligned}
$$

That is, $F(x) \in \bar{U}\left(x_{0}, t^{*}\right)$.

Using (13) and (15) for $x \in \bar{U}\left(x_{0}, t^{*}\right)$, we get

$$
\begin{aligned}
\left\|A_{0}^{-1}\left[A_{0}-\left(I-F^{\prime}(F(x))\right)\right]\right\| & \leq\left\|A_{0}^{-1}\left(F^{\prime}\left(F\left(x_{0}\right)\right)-F^{\prime}(F(x))\right)\right\| \\
& \leq \ell_{0}\left\|F\left(x_{0}\right)-F(x)\right\| \leq \ell_{0} a_{0}\left\|x_{0}-x\right\| \\
& \leq \ell_{0} a_{0} t^{*}<1,
\end{aligned}
$$


by the choice of $t^{*}$. It follows from (27) and the Banach Lemma on invertible operators [7] that $A(x)=I-F^{\prime}(F(x))$ is invertible with

$$
\left\|A(x)^{-1} A_{0}\right\| \leq\left[1-\ell_{0} a_{0}\left\|x_{0}-x\right\|\right]^{-1} .
$$

By (2) we get

$$
\begin{aligned}
x_{k+1}-F\left(x_{k+1}\right)= & x_{k}-A_{k}^{-1}\left(x_{k}-F\left(x_{k}\right)\right)-F\left(x_{k+1}\right) \\
= & A_{k}^{-1}\left[A_{k}\left(x_{k}-F\left(x_{k+1}\right)\right)-\left(x_{k}-F\left(x_{k}\right)\right)\right] \\
= & A_{k}^{-1}\left[F\left(x_{k}\right)-F\left(x_{k+1}\right)-F^{\prime}\left(F\left(x_{k}\right)\right)\left(x_{k}-x_{k+1}\right)\right. \\
& \left.-F^{\prime}\left(F\left(x_{k}\right)\right)\left(x_{k+1}-F\left(x_{k+1}\right)\right)\right],
\end{aligned}
$$

so

$$
\begin{aligned}
x_{k+1}-F\left(x_{k+1}\right)+ & A_{k}^{-1} F^{\prime}\left(F\left(x_{k}\right)\right)\left(x_{k+1}-F\left(x_{k+1}\right)\right) \\
& =A_{k}^{-1}\left[F\left(x_{k}\right)-F\left(x_{k+1}\right)-F^{\prime}\left(F\left(x_{k}\right)\right)\left(x_{k}-x_{k+1}\right)\right],
\end{aligned}
$$

hence

$$
\begin{aligned}
\left\{I+A_{k}^{-1} F^{\prime}\left(F\left(x_{k}\right)\right)\right\} & \left(x_{k+1}-F\left(x_{k+1}\right)\right) \\
& =A_{k}^{-1}\left[F\left(x_{k}\right)-F\left(x_{k+1}\right)-F^{\prime}\left(F\left(x_{k}\right)\right)\left(x_{k}-x_{k+1}\right)\right],
\end{aligned}
$$

and therefore

$$
\begin{aligned}
& x_{k+1}-F\left(x_{k+1}\right)=F\left(x_{k}\right)-F\left(x_{k+1}\right)-F^{\prime}\left(F\left(x_{k}\right)\right)\left(x_{k}-x_{k+1}\right) \\
= & \int_{0}^{1}\left[F^{\prime}\left(\theta x_{k}+(1-\theta) x_{k+1}\right)-F^{\prime}\left(\theta F\left(x_{k}\right)+(1-\theta) F\left(x_{k}\right)\right)\right]\left(x_{k}-x_{k+1}\right) d \theta .
\end{aligned}
$$

By composing both sides of (29) with $A_{0}^{-1}$ and using (14), (16), we get

$$
\begin{aligned}
\| A_{0}^{-1}\left(x_{k+1}-\right. & \left.F\left(x_{k+1}\right)\right) \| \\
\leq & \frac{\ell}{2}\left[\left\|x_{k}-F\left(x_{k}\right)\right\|+\left\|x_{k+1}-F\left(x_{k}\right)\right\|\right]\left\|x_{k+1}-x_{k}\right\|, \\
\left\|x_{k}-F\left(x_{k}\right)\right\| \leq & \left\|I+F^{\prime}\left(F\left(x_{k}\right)\right)\right\| \cdot\left\|x_{k+1}-x_{k}\right\| \\
\leq & (1+b)\left\|x_{k+1}-x_{k}\right\| \\
\left\|x_{k+1}-F\left(x_{k}\right)\right\| & \leq\left\|x_{k+1}-x_{k}\right\|+\left\|x_{k}-F\left(x_{k}\right)\right\| \\
& \leq\left\|x_{k+1}-x_{k}\right\|+(1+b)\left\|x_{k+1}-x_{k}\right\| \\
& =(2+b)\left\|x_{k+1}-x_{k}\right\| .
\end{aligned}
$$

Moreover by (2), (28)-(32), we get

$$
\begin{aligned}
\left\|x_{k+2}-x_{k+1}\right\| & \leq\left\|A_{k+1}^{-1} A_{0}\right\| \cdot\left\|A_{0}^{-1}\left(x_{k+1}-F\left(x_{k+1}\right)\right)\right\| \\
& \leq \frac{\ell}{2} \frac{3+2 b}{1-\ell_{0} a_{0}\left\|x_{k+1}-x_{0}\right\|}\left\|x_{k+1}-x_{k}\right\|^{2} \\
& \leq \frac{L}{2\left(1-L_{0} t_{k+1}\right)}\left(t_{k+1}-t_{k}\right)^{2}=t_{k+2}-t_{k+1} .
\end{aligned}
$$


Thus for every $z \in \bar{U}\left(x_{k+2}, t^{*}-t_{k+1}\right)$ we have

$$
\begin{aligned}
\left\|z-x_{k+1}\right\| & \leq\left\|z-x_{k+2}\right\|+\left\|x_{k+2}-x_{k+1}\right\| \\
& \leq t^{*}-t_{k+2}+t_{k+2}-t_{k+1}=t^{*}-t_{k+1} .
\end{aligned}
$$

That is,

$$
z \in \bar{U}\left(x_{k+1}, t^{*}-t_{k+1}\right)
$$

Estimates (33) and (34) imply that (25) and (26) hold for $n=k+1$.

Theorem 1 implies that $\left\{t_{n}\right\}(n \geq 0)$ is a Cauchy sequence. From (25) and $(26)\left\{x_{n}\right\}(n \geq 0)$ is also a Cauchy sequence, and so it converges to some $x^{*} \in \bar{U}\left(x_{0}, t^{*}\right)$ (since $\bar{U}\left(x_{0}, t^{*}\right)$ is a closed set) such that

$$
\left\|x^{*}-x_{k}\right\| \leq t^{*}-t_{k} .
$$

The combination of (33) and (34) yields $F\left(x^{*}\right)=x^{*}$.

To show uniqueness let $y^{*}$ be a fixed point of $F$ in $U\left(x_{0}, R\right)$. By (2) we obtain the approximation

$$
\begin{aligned}
x_{k+1}-y^{*}= & x_{k}-y^{*}-A_{k}^{-1}\left(x_{k}-F\left(x_{k}\right)\right) \\
= & A_{k}^{-1}\left\{F\left(x_{k}\right)-F\left(y^{*}\right)-F^{\prime}\left(F\left(x_{k}\right)\right)\left(x_{k}-y^{*}\right)\right\} \\
= & {\left[A_{k}^{-1} A_{0}\right] A_{0}^{-1}\left\{\int _ { 0 } ^ { 1 } \left[F^{\prime}\left(\theta x_{k}+(1-\theta) y^{*}\right)\right.\right.} \\
& \left.\left.\quad-F^{\prime}\left(\theta F\left(x_{k}\right)+(1-\theta) F\left(x_{k}\right)\right)\right]\left(x_{k}-y^{*}\right) d \theta\right\} .
\end{aligned}
$$

Hence, by (36) and (13)-(16), (24) we obtain

$$
\begin{aligned}
\left\|x_{k+1}-y^{*}\right\| & \leq \frac{\ell}{2} \frac{\left\|x_{k}-F\left(x_{k}\right)\right\|+\left\|F\left(x_{k}\right)-F\left(y^{*}\right)\right\|}{1-\ell_{0} a_{0}\left\|x_{k}-x_{0}\right\|}\left\|x_{k}-y^{*}\right\| \\
& \leq \frac{\ell}{2} \frac{(1+b)\left\|x_{k+1}-x_{k}\right\|+a\left\|x_{k}-y^{*}\right\|}{1-\ell_{0} a_{0}\left\|x_{k}-x_{0}\right\|}\left\|x_{k}-y^{*}\right\| \\
& <\frac{\ell}{2} \frac{(1+b) \eta+a R}{1-\ell_{0} a_{0} t^{*}}\left\|x_{k}-y^{*}\right\|<\left\|x_{k}-y^{*}\right\|,
\end{aligned}
$$

which shows $\lim _{k \rightarrow \infty} x_{k}=y^{*}$. But we already showed $\lim _{k \rightarrow \infty} x_{k}=x^{*}$. That is,

$$
x^{*}=y^{*} .
$$

Finally the uniqueness in $\bar{U}\left(x_{0}, t^{*}\right)$ follows from (37) and (23) (holding as strict inequality).

That completes the proof of Theorem 2.

Remark 1. Condition (23) can be dropped. We can replace it by

$$
\ell(1+b) \eta+a_{0}\left(t^{*}+R\right)+2 \ell_{0} a_{0} t^{*} \leq 2 .
$$


Indeed, we have

$$
\begin{aligned}
& \leq \frac{\ell}{2} \frac{(1+b)\left\|x_{k+1}-x_{k}\right\|+\left\|F\left(x_{k}\right)-F\left(x_{0}\right)+F\left(x_{0}\right)-F\left(y^{*}\right)\right\|}{1-\ell_{0} a_{0}\left\|x_{k}-x_{0}\right\|}\left\|x_{k}-y^{*}\right\| \\
& \leq \frac{\ell}{2} \frac{\left\|x_{k+1}-x_{k}\right\|+a_{0}\left(\left\|x_{0}-x_{k}\right\|+\left\|x_{0}-y^{*}\right\|\right)}{1-\ell_{0} a_{0}\left\|x_{k}-x_{0}\right\|}\left\|x_{k}-y^{*}\right\| \\
& <\frac{\ell}{2} \frac{(1+b) \eta+a_{0}\left(t^{*}+\eta\right)}{1-\ell_{0} a_{0} t^{*}}\left\|x_{k}-y^{*}\right\|,
\end{aligned}
$$

which also shows $\lim _{k \rightarrow \infty} x_{k}=y^{*}$. Hence, again we get $x^{*}=y^{*}$.

3. Local analysis of Stirling's method. Below we show the main local convergence theorem for Stirling's method (2).

TheOREm 2. Let $F: D \subseteq X \rightarrow X$ be a Fréchet differentiable operator. Assume that there exist a fixed point $x^{*}$ of the operator $F$ such that

$$
A_{*}=I-F^{\prime}\left(F\left(x^{*}\right)\right)
$$

is invertible, and parameters $\alpha \geq 0, \beta \in[0,1], \gamma \geq 0$ such that

$$
\begin{aligned}
\left\|A_{*}^{-1}\left[F^{\prime}\left(F\left(x^{*}\right)\right)-F^{\prime}(F(x))\right]\right\| & \leq \alpha\left\|F\left(x^{*}\right)-F(x)\right\|, \\
\left\|F\left(x^{*}\right)-F(x)\right\| & \leq \beta\left\|x^{*}-x\right\|, \\
\left\|A_{*}^{-1}\left(F^{\prime}(x)-F^{\prime}(y)\right)\right\| & \leq \gamma\|x-y\|
\end{aligned}
$$

for all $x, y, F(x) \in D$, and

$$
U\left(x^{*}, r^{*}\right) \subseteq D
$$

where

$$
\begin{aligned}
r^{*} & =\frac{2}{p+2 q}, \\
p & =\gamma(1+2 \beta), \quad q=\alpha \beta .
\end{aligned}
$$

Then $\left\{x_{n}\right\}(n \geq 0)$ generated by Stirling's method (2) is well defined, remains in $U\left(x^{*}, r^{*}\right)$ for all $n \geq 0$, and converges to $x^{*}$ provided that $x_{0} \in U\left(x^{*}, r^{*}\right)$. Moreover the following error bounds hold for all $n \geq 0$ :

$$
\left\|x_{n+1}-x^{*}\right\| \leq \frac{p}{2} \frac{1}{1-q\left\|x_{n}-x^{*}\right\|}\left\|x_{n}-x^{*}\right\|^{2} .
$$

Proof. Let $x \in U\left(x^{*}, r^{*}\right)$. Using (41), (42) we get

$$
\begin{aligned}
\left\|A_{*}^{-1}\left[A_{*}-\left(I-F^{\prime}(F(x))\right)\right]\right\| & \leq \alpha\left\|F\left(x^{*}\right)-F(x)\right\| \leq \alpha \beta\left\|x-x^{*}\right\| \\
& \left.<\alpha \beta r^{*}<1 \quad \text { (by the choice of } r^{*}\right),
\end{aligned}
$$

and $F(x) \in U\left(x^{*}, r^{*}\right)$, since

$$
\left\|F(x)-x^{*}\right\|=\left\|F(x)-F\left(x^{*}\right)\right\| \leq \beta\left\|x-x^{*}\right\|<\beta r^{*} \leq r^{*} .
$$


Hence, by (48) and the Banach Lemma on invertible operators, $I-F^{\prime}(F(x))$ is invertible, and

$$
\left\|\left(I-F^{\prime}(F(x))\right)^{-1} A_{*}\right\| \leq \frac{1}{1-q\left\|x-x^{*}\right\|} .
$$

By hypothesis $x_{0} \in U\left(x^{*}, r^{*}\right)$. Assume $x_{k} \in U\left(x^{*}, r^{*}\right), k=0,1, \ldots, n$.

As in (36) we obtain the approximation

$$
\begin{aligned}
x_{k+1}-x^{*}= & {\left[A_{k}^{-1} A_{*}\right] A_{*}^{-1}\left\{\int _ { 0 } ^ { 1 } \left[F^{\prime}\left(\theta x_{k}+(1-\theta) x^{*}\right)\right.\right.} \\
& \left.\left.-F^{\prime}\left(\theta F\left(x_{k}\right)+(1-\theta) F\left(x_{k}\right)\right)\right]\right\}\left(x_{k}-x^{*}\right) d \theta .
\end{aligned}
$$

By (51), (41)-(43) we get

$$
\begin{gathered}
\left\|x_{k+1}-x^{*}\right\| \leq \frac{\gamma}{2} \frac{\left\|x_{k}-F\left(x_{k}\right)\right\|+\left\|F\left(x_{k}\right)-F\left(x^{*}\right)\right\|}{1-q\left\|x_{k}-x^{*}\right\|}\left\|x_{k}-x^{*}\right\|, \\
\left\|x_{k}-F\left(x_{k}\right)\right\| \leq\left\|x_{k}-x^{*}\right\|+\left\|F\left(x^{*}\right)-F\left(x_{k}\right)\right\| \leq(1+\beta)\left\|x_{k}-x^{*}\right\| .
\end{gathered}
$$

Therefore we obtain

$$
\left\|x_{k+1}-x^{*}\right\| \leq \frac{\gamma}{2} \frac{(1+\beta)\left\|x_{k}-x^{*}\right\|+\beta\left\|x_{k}-x^{*}\right\|}{1-\alpha \beta\left\|x_{k}-x^{*}\right\|}\left\|x_{k}-x^{*}\right\|<\left\|x_{k}-x^{*}\right\|,
$$

which shows $x_{k+1} \in U\left(x^{*}, r^{*}\right)$ and $\lim _{k \rightarrow \infty} x_{k}=x^{*}$.

That completes the proof of Theorem 3 .

REMARK 2. As noted in [3]-[6], [11] the local results obtained here can be used for projection methods such as Arnoldi's, the generalized minimum residual method (GMRES), the generalized conjugate method (GCR), for combined Stirling's finite difference projection methods and in connection with the mesh independence principle in order to develop the cheapest and most efficient mesh refinement strategies [4], [6].

REMARK 3. The local results obtained here can also be used to solve (1), where $F^{\prime}$ satisfies the autonomous differential equation [3], [4], [7]

$$
F^{\prime}(x)=T(F(x)),
$$

where $T: X \rightarrow X$ is a known continuous operator. Since $F^{\prime}\left(F\left(x^{*}\right)\right)=$ $T\left(F\left(F\left(x^{*}\right)\right)\right)=T(F(0))$, we can apply the results obtained here without actually knowing the fixed point $x^{*}$ of $F$.

We finally complete this study with a numerical example:

ExAmple 1 . Let $X=D=U(0,1)$ and define $F$ on $D$ by

$$
F(x)=e^{x}-x-1 \text {. }
$$


Using (40)-(43), (45), (46) and (55) we obtain (for $x^{*}=0$ )

$$
\alpha=e-1, \quad \beta=e-2, \quad \gamma=e
$$

and

$$
r^{*}=.219981153 \text {. }
$$

The results obtained in [8] require

$$
\left\|F^{\prime}(x)\right\|<1 \quad \text { for all } x \in D \text {. }
$$

But (55) gives

$$
\left\|F^{\prime}(x)\right\| \leq a=e-1>1 \text {. }
$$

Hence, these results cannot be used here. Note that Theorem 2 does not require $a \in[0,1)$ but $a_{0} \in[0,1)$ where $a_{0} \leq a$ (in general) and $a / a_{0}$ can be arbitrarily large [3], [4], [7]. Using

$$
\left\|F^{\prime}\left(x^{*}\right)^{-1}\left[F^{\prime}(x)-F^{\prime}(y)\right]\right\| \leq w\|x-y\|,
$$

Rheinboldt [9] showed that the convergence radius for Newton's method

$$
x_{n+1}=x_{n}-F^{\prime}\left(x_{n}\right)^{-1} F\left(x_{n}\right) \quad\left(x_{0} \in D, n \geq 0\right)
$$

is given by

$$
r=\frac{2}{3 w} .
$$

However $w$ cannot be computed here since $F^{\prime}\left(x^{*}\right)$ is not invertible.

\section{References}

[1] I. K. Argyros, Accessibility of solutions of equations on Banach spaces by a Stirlinglike method, Rev. Acad. Cienc. Zaragoza 54 (1999), 93-98.

[2] -, A new convergence theorem for Stirling's method in Banach space, Atti Sem. Mat. Fis. Univ. Modena 48 (2000), 225-233.

[3] -, Advances in the Efficiency of Computational Methods and Applications, World Sci., River Edge, NJ, 2000.

[4] I. K. Argyros and F. Szidarovszky, The Theory and Applications of Iteration Methods, CRC Press, Boca Raton, FL, 1993.

[5] P. N. Brown, A local convergence theory for combined inexact-Newton/finite-difference projection methods, SIAM J. Numer. Anal. 24 (1987), 407-434.

[6] P. Deuflhard and F. A. Potra, Asymptotic mesh independence of Newton-Galerkin methods via a refined Mysovskiu theorem, ibid. 29 (1992), 1395-1412.

[7] L. V. Kantorovich and G. P. Akilov, Functional Analysis in Normed Spaces, Pergamon Press, Oxford, 1982.

[8] L. B. Rall, Convergence of Stirling's method in Banach spaces, Aequationes Math. 12 (1973), 12-20.

[9] W. C. Rheinboldt, An adaptive continuation process for solving systems of nonlinear equations, in: Banach Center Publ. 3, Polish Sci. Publ., 1977, 129-142. 
[10] J. Stirling, Methodus Differentialis: sive tractatus de summatione et interpolatione serierum infinitarum, W. Boyer, London, 1730.

[11] T. J. Ypma, Local convergence of inexact Newton methods, SIAM J. Numer. Anal. 21 (1984), 583-590.

Department of Mathematics

Cameron University

Lawton, OK 73505, U.S.A.

E-mail: Ioannisa@cameron.edu

Received on 8.7.2002;

revised version on 18.11 .2002 